\title{
Kounis Syndrome Associated With Selective Anaphylaxis to Cefazolin
}

\author{
Sequeira $\mathrm{T}^{1}$, Gaspar $\hat{\mathrm{A}}^{2}$, Mota $\mathrm{I}^{2}$, Correia $\mathrm{M}^{2}$, Chambel $\mathrm{M}^{2}$, \\ Morais-Almeida $\mathrm{M}^{2}$ \\ ${ }^{1}$ Pulmonology Department, Prof. Doutor Fernando Fonseca \\ Hospital, Lisbon, Portugal \\ ${ }^{2}$ Immunoallergy Department, CUF Descobertas Hospital, Lisbon, \\ Portugal
}

J Investig Allergol Clin Immunol 2018; Vol. 28(4): 257-258 doi: $10.18176 /$ jiaci.0248

Key words: Kounis syndrome. Anaphylaxis. Cefazolin. First-generation cephalosporin.

Palabras clave: Síndrome de Kounis. Anafilaxia. Cefazolina. Cefalosporina de primera generación.

Kounis syndrome (KS) was first described in 1991 by Kounis and Zavras [1]. The syndrome is characterized by the simultaneous presence of anaphylactic and cardiac events [1]. $\mathrm{KS}$ is also known as allergic angina or allergic myocardial infarction. It is thought that following an allergic stimulus, inflammatory mediators are released by mast cells, leading to spastic contraction of coronary smooth muscle cells $[2,3]$. Three types of KS have been described [4], as follows: type I, coronary vasospasm without significant coronary disease; type II, patients with pre-existing coronary disease in which the release of pro-inflammatory mediators (histamine, leukotrienes and serotonin) can cause vasospasm or instability of atherosclerotic plaques; and type III, in which drugeluting stent thrombosis is associated with a hypersensitivity reaction [5]. Although several drugs (antibiotics, nonsteroidal anti-inflammatory drugs, anticoagulants, corticosteroids, anesthetics, and contrast media) have been associated with KS, antibiotics are the most frequently involved [6,7]. Recently, Renda et al [8] identified the largest case series on KS associated with antibiotics, with $37.5 \%$ of all cases involving amoxicillin/clavulanic acid (6 cases) and the remaining 10 cases caused by amoxicillin alone, piperacillin/tazobactam, ceftriaxone, cefazolin, levofloxacin, and metronidazole.

We report the case of a 56-year-old man who developed KS immediately after intravenous administration of cefazolin. To the best of our knowledge, this is the first case of KS with selective anaphylaxis to cefazolin. Sánchez et al [9] reported type I KS due to rocuronium and/or cefazolin with positive skin test results to both drugs, although, given that the authors did not present any further data (skin test with the remaining ß-lactams or drug provocation tests), we cannot consider this case to be clearly selective or even caused only by cefazolin.

The patient had a medical history of dyslipidemia and no personal history of allergy, although he did have a family history of drug allergy (brother with a history of penicillin allergy). He underwent knee arthroscopy (for meniscus tear), with no complications during the procedure. He was always kept under 
close observation in the operating room through pulse oximetry, noninvasive blood pressure, and ECG. In the postoperative period, 8 hours after surgery and less than 5 minutes after intravenous administration of cefazolin, the patient experienced severe hypotension (blood pressure, $60-40 \mathrm{mmHg}$ ) and desaturation (peripheral oxygen saturation, 62\%) associated with a pattern of right cardiac overload (S1Q3T3) with diffuse ST depression on ECG and a peak troponin I level of $7 \mathrm{ng} / \mathrm{mL}$ (normal $<0.06 \mathrm{ng} / \mathrm{mL}$ ). Transthoracic echocardiography revealed segmental alterations and compromised left ventricle systolic function that led to a coronary angiography, which revealed severe right coronary spasm, with no further disease. The patient was treated in the intensive care unit with epinephrine, clemastine, hydrocortisone, and ranitidine. After coronary angiography, norepinephrine and isosorbide dinitrate were administered by perfusion, with a good response. After 7 days, the patient was discharged with no symptoms and normal ECG and transthoracic echocardiography findings. After discharge, the patient was sent to the immunoallergy department for further study.

The allergology work-up was performed according to the recommendations of the European Network of Drug Allergy/ European Academy of Allergy and Clinical Immunology [10]. Serum-specific IgE antibodies and skin testing were performed at a 4-week interval after the clinical reaction; skin testing was a crucial step for assessing cross-reactivity within the $\beta$-lactam antibiotics, including cephalosporins. $\beta$-Lactam skin testing was performed with solutions of benzylpenicilloyl octa-Llysine (PPL), sodium benzylpenilloate (minor determinant [MD]), and amoxicillin (DAP, Diater), as well as penicillin G, cefazolin, cefuroxime, and ceftriaxone [10]. Specific IgE testing (ImmunoCAP, Thermo Fisher) for penicillin G, penicillin $\mathrm{V}$, amoxicillin, ampicillin, and cefaclor was negative $(<0.10 \mathrm{kU} / \mathrm{L})$. Skin testing was performed after written informed consent was provided. Skin prick test results were negative to all $\beta$-lactam antibiotics, as well as to latex. Intradermal testing with cefazolin was positive at a concentration of $2.5 \mathrm{mg} / \mathrm{mL}$ (wheal, $13 \mathrm{~mm}$ ), with erythema and pruritus in the immediate reading (20 minutes). All intradermal tests with the other $\beta$-lactam antibiotics were negative: PPL $5 \times 10^{-5} \mathrm{mM}$, MD $2 \times 10^{-5} \mathrm{mM}$, penicillin G 10000 $\mathrm{IU} / \mathrm{mL}$, amoxicillin $20 \mathrm{mg} / \mathrm{mL}$, cefuroxime $2.5 \mathrm{mg} / \mathrm{mL}$, and ceftriaxone $2.5 \mathrm{mg} / \mathrm{mL}$. There were no late reactions. Since the anaphylactic reaction occurred during the postoperative period, the anesthetic drugs administered during surgery (midazolam, fentanyl, rocuronium, and propofol) 8 hours before the reaction were ruled out.

At a subsequent appointment, the patient was successfully challenged with amoxicillin (total cumulative dose of $1010 \mathrm{mg}$ ). The patient subsequently tolerated cefuroxime.

We conclude that the patient fulfilled the criteria for the diagnosis of KS (type I), with a severe and selective IgE-mediated allergy to cefazolin. Allergy to penicillin derivatives and to second- and third-generation cephalosporins was excluded.

Although considered a rare syndrome, KS is increasingly reported, possibly reflecting increased awareness of this syndrome. A large percentage of the reported cases occurred with antibiotics, more precisely with amoxicillin/clavulanic acid, and very few cases have been shown to be related to other antibiotics. To our knowledge, this is the first case of KS with confirmed selective IgE-mediated allergy to cefazolin.

\section{Funding}

The authors declare that no funding was received for the present study.

Conflicts of Interest

The authors declare that they have no conflicts of interest.

\section{References}

1. Kounis NG, Zavras GM. Histamine-induced coronary artery spasm: the concept of allergic angina. $\mathrm{Br} J$ Clin Pract. 1991;45(2):121-8.

2. Steffel J, Akhmedov A, Greutert H, Lüscher TF, Tanner FC. Histamine induces tissue factor expression: implications for acute coronary syndromes. Circulation. 2005;112(3):341-9.

3. Lanza GA, Careri G, Crea F. Mechanisms of coronary artery spasm. Circulation. 2011;124(16):1774-82.

4. Kounis NG, Mazarakis A, Tsigkas G, Giannopoulos S, Goudevenos J. Kounis syndrome: a new twist on an old disease. Future Cardiol. 2011;7(6):805-24.

5. Akyel A, Murat SN, Cay S, Kurtul A, Ocek AH, Cankurt T. Late drug eluting stent thrombosis due to acemetacine: type III Kounis syndrome: Kounis syndrome due to acemetacine. Int J Cardiol. 2012;155(3):461-2.

6. Lombardi N, Pugi A, Maggini V, Lenti MC, Mugelli A, Cecchi $E_{\text {, et }}$ al. Underdiagnosis and pharmacovigilance. The case of allergic acute coronary syndrome (Kounis syndrome). Int J Cardiol. 2013;168(5):5054-5.

7. Renda F, Landoni G, Trotta F, Piras D, Finco G, Felicetti P, et al. Kounis Syndrome: An analysis of spontaneous reports from international pharmacovigilance database. Int J Cardiol. 2016;203:217-20

8. Renda F, Marotta E, Landoni G, Belletti A, Cuconato V, Pani L. Kounis syndrome due to antibiotics: A global overview from pharmacovigilance databases. Int J Cardiol. 2016;224:406-11.

9. Sánchez VO, Roca LC, Moreno Adel P. Intraoperative "Kounis syndrome" that improved electrocardiography changes and hemodynamic situation after administering nitroglycerine. Braz J Anesthesiol. 2014;64(4):281-5.

10. Brockow K, Garvey LH, Aberer W, Atanaskovic-Markovic M, Barbaud A, Bilo MB, et al; ENDA/EAACI Drug Allergy Interest Group. Skin test concentrations for systemically administered drugs - an ENDA/EAACI Drug Allergy Interest Group position paper. Allergy. 2013;68(6):702-12.

- Manuscript received November 1, 2017; accepted for publication February 27, 2018.

Ângela Gaspar

Immunoallergy Department, CUF Descobertas Hospital Rua Mário Botas, 1998-018 Lisboa, Portugal E-mail: angela.gaspar@sapo.pt 